\title{
Strategic Behavior and Market Design in Regional Climate Policy
}

\author{
Brittany L. Tarufelli*
}

\begin{abstract}
U.S. electricity markets vary by region and imperfectly overlap with regional climate policies. Although emissions leakage across emissions-regulated and -unregulated areas may depend on regional market design, and the extent of trading between market designs, previous studies of leakage from regional climate policies have focused on market power and market efficiency within only a centralized region following market rules. I develop a theoretical model which considers a second-best problem where a climate policy to correct for a negative externality from carbon emissions can be distorted by another market failure from the market design itself. My model allows for several types of non-overlapping climate policies and electricity market designs, and generates leakage predictions for these combinations.
\end{abstract}

Keywords: Electric Utilities, Air Pollution, Market Structure, Environmental Economics: Government Policy

JEL: L94, Q53, L10, Q58

\section{INTRODUCTION}

Heterogeneity in market design can lead to unanticipated outcomes from sub-global climate policies. I consider a second-best problem where the efficacy of a sub-global climate policy to correct for one market failure - a negative externality from carbon emissions—can be distorted by a second market failure from the market design itself. I examine this problem in the context of U.S. electricity markets, as market designs vary by region and imperfectly overlap with regional climate policies such as carbon prices and renewables subsidies. While regional climate policies to cut carbon emissions overlap regions with different electricity market designs, previous studies of leakage from regional climate

*Corresponding author. Center for Energy Studies, Louisiana State University, Energy, Coast and Environment Bldg., Baton Rouge LA, 70803. E-mail: btarufelli@1su.edu. 
policies in electricity have not taken market design into account. Instead, previous studies have been focused on market power and market efficiency within a centralized region following market rules. ${ }^{1}$

I model strategic behavior in electricity markets when market designs and emissions policies are partially overlapping. My model also allows for several types of non-overlapping policies and market designs. For example, sub-regions within a given market design may have their own climate policies. Leakage across emissions-regulated and -unregulated areas within a given market region may depend on the market design. Alternatively, trading across market regions with differing market designs may occur, and emissions policies may be more prevalent under one design than another. My model generates predictions for these combinations.

There are two predominant wholesale electricity market designs in the U.S., those regions that have restructured and operate under a centralized auction market design, which I will refer to as centralized markets, and those regions operating under a decentralized bilateral trading system, which I will refer to as bilateral markets. Despite changes to market rules to encourage competition, market power persists in wholesale electricity markets. ${ }^{2}$ The potential for exercising market power in such markets is due to some unique characteristics of electricity markets—primarily that electricity cannot easily be stored, creating opportunities for exercising market power when there are short-term supply and demand imbalances. To facilitate the challenge of balancing supply and demand, electricity trading takes place in forward contract and spot markets. Forward contract markets are used to make financial transactions to plan for and commit to electricity production for future use. Spot markets are for electricity production, distribution, and incremental trades to address last-minute supply and demand imbalances.

In related market design literature, ${ }^{3}$ there are two main approaches used to model strategic producer behavior in imperfectly competitive wholesale electricity markets: the Cournot model ${ }^{4}$ and the supply function equilibria model (SFE) ${ }^{5}$ (Willems et al., 2009). I examine strategic behavior when market designs and emissions policies are partially overlapping with a Cournot model for its ability to accommodate relevant market details. Because Cournot models tend to overpredict prices, I include a forward contract market to reduce firms' sensitivity to prices in the spot market (Allaz and Vila, 1993). Bushnell et al. (2008) confirmed that after accounting for forward contracts, the

\footnotetext{
${ }^{1}$ See Fowlie (2009), for example.

${ }^{2}$ Borenstein et al. (1999), Chen and Hobbs (2005), Puller (2007), Sweeting (2007), Hortaçsu and Puller (2008), and Bushnell et al. (2008) find evidence of market power in empirical studies of electricity markets.

${ }^{3}$ This literature focuses on strategic behavior modeled with game theory approaches. There is a vast literature on electricity market modeling approaches, for a review see Li et al. (2011).

${ }^{4}$ See Cardell et al. (1997), Andersson and Bergman (1995), Chen and Hobbs (2005), Bushnell et al. (2008), Fowlie (2009).

${ }^{5}$ See Green and Newbery (1992), Green (1999), Holmberg (2008), Hortaçsu and Puller (2008), Anderson (2013).
} 
Cournot model predicted prices that did not deviate significantly from observed electricity prices. For an extended discussion of modeling approaches in electricity markets, see Appendix B.

My research question is most similar to that of Fowlie (2009), who uses a Cournot model with a forward contract market to show that institutional details matter for emissions leakage predictions. By extending the model of Allaz and Vila (1993) to include a carbon price, Fowlie (2009) finds that leakage is greater with increased competition from the pro-competitive effect of a forward contract market. ${ }^{6}$ Different from Fowlie (2009), who assumes that all producers' forward contracts are bought by speculators, I explicitly model the decisions of electricity producers and retailers in the forward contract and spot market stages of the model. My approach more closely resembles Powell (1993), who clears the forward market with the intersection of demand for forward contracts from retailers and supply of forward contracts from producers.

When Cournot models with forward contract markets are utilized, the assumption of how the forward contract market clears affects the extent of the forward contract market and the competitiveness of the spot market. Arbitrage is a standard assumption in related literature (Allaz and Vila, 1993; Green, 1999; Fowlie, 2009), but not all electricity markets have financial instruments that allow for arbitrage. In an extensive finance literature, it has been shown that in the absence of arbitrage, models can be solved via general equilibrium asset pricing, where agents' mean-variance preferences affect strategic forward contract positions and resulting spot market prices (Bessembinder and Lemmon, 2002; Anderson and Danthine, 1980; Hirshleifer and Subrahmanyam, 1993). In lieu of mean-variance preferences, I utilize a conditional value at risk $(\mathrm{CVaR})$ measure, which is a coherent risk measure (Rockafellar and Uryasev, 2000). ${ }^{7}$

In my two-stage Cournot model, in the second stage, shocks from demand and renewable resources are realized and the spot market must clear. Oligopoly producers then engage in Cournot competition, taking as given the forward contract positions from the first stage to determine the final spot price, quantity of electricity produced, and resulting emissions levels. I approximate centralized

\footnotetext{
${ }^{6}$ Note that Fowlie (2009) focuses on emissions leakage from market design. Other papers focus on emissions leakage from the design of cap-and-trade programs, highlighting the importance of the allocation of emissions permits and the point of regulation, see for example Bushnell and Mansur (2011), Chen et al. (2011), Bushnell and Chen (2012), and Bushnell et al. (2014).

${ }^{7}$ The mean-variance model achieves maximum expected utility only if (1) distributions are assumed to be normal or (2) utility is quadratic (Levy and Markowitz, 1979). Both assumptions can be problematic, as real world probability distributions are often not normal and quadratic utility functions display increasing absolute risk aversion. With non-normal distributions, mean-variance preferences will still hold with quadratic utility, but because of the increasing absolute risk aversion, the mean-variance model is generally less widely used in recent literature. More recent approaches to portfolio management minimize a CVaR measure to reduce risk (Rockafellar and Uryasev, 2000). CVaR is a coherent risk measure (Artzner et al., 1999), satisfying the axioms of monotonicity, translation equivariance, sub-additivity, and positive homogeneity. When losses are normal, the CVaR will return the same optimal portfolio as the value at risk (VaR) and the Markowitz mean-variance model (Rockafellar and Uryasev, 2000). But when losses are not normal, CVaR remains a coherent risk measure, improving on other risk measures. Rockafellar and Uryasev (2002) provide a framework for determining the CVaR under general loss distributions.
} 
and bilateral market designs by making assumptions about the extent of competition in each of the forward contract and spot markets, as well as whether financial speculators can participate in the markets. I assess how incomplete regulation-regulation that is only applied to some producers within a bilateral or centralized region—can affect emissions leakage for electricity producers operating under each market design. I define leakage as in Fowlie (2009), where leakage is the difference between emissions from unregulated producers under incomplete regulation, and emissions of those producers under no regulation.

As shown in Figure 1, I find that emissions leakage depends on the relative market power in centralized market regions vs. bilateral regions. Relative market power is driven by market design, where centralized markets are more competitive for a given number of players. Three key results are a) when a carbon emissions price is asymmetrically applied ${ }^{8}$ to a bilateral region, emissions leakage is low; b) when a carbon emissions price is asymmetrically applied to a centralized region, emissions leakage is high; and c) if a carbon emissions price is applied to a centralized region and emissions leakage is to a bilateral region, leakage is again low, but increases if the bilateral region trades with the centralized region. Emissions leakage increases in more competitive markets, because producers' production and relative market shares are more responsive to relative changes in marginal costs as in Fowlie (2009), but the less competitive bilateral market can act as a structural backstop to emissions leakage.

My framework can be used as a foundation for building more detailed models of the electricity industry and to inform climate policy design when regulations overlap differing electricity market designs. For example, in 2014, the California Independent System Operator (CAISO) extended a centralized spot market over a traditionally bilateral Western electric region with the introduction of the Western Energy Imbalance Market (EIM), integrating states and regions with diverse climate policies. In February 2021, the Southwest Power Pool (SPP) launched its Western Energy Imbalance Services market, allowing more utilities from the traditionally bilateral Western electric region to join its centralized spot market. ${ }^{9}$ The European Union's Energy Union also continues to further integrate diverse member states' energy markets to support the clean energy transition. ${ }^{10}$ Recent initiatives, like the European Cross-Border Intraday market (XBID) further integrate electricity markets across member states with diverse climate policies. ${ }^{11}$

\footnotetext{
${ }^{8} \mathrm{~A}$ carbon emissions price is applied to only some firms in a region, leading to incomplete regulation.

${ }^{9}$ https://spp.org/newsroom/press-releases/southwest-power-pool-expands-offerings-towestern-utilities-with-launch-of-new-electricity-market/ (accessed 2/22/2021).

${ }^{10}$ https://ec.europa.eu/energy/topics/energy-strategy/energy-union/fifth-report-state-energyunion_en (accessed 2/22/2021).

${ }^{11}$ https://wWw . entsoe. eu/news/2018/06/14/european-cross-border-intraday-xbid-solution-and-
} 
Figure 1: Emissions Leakage Predictions

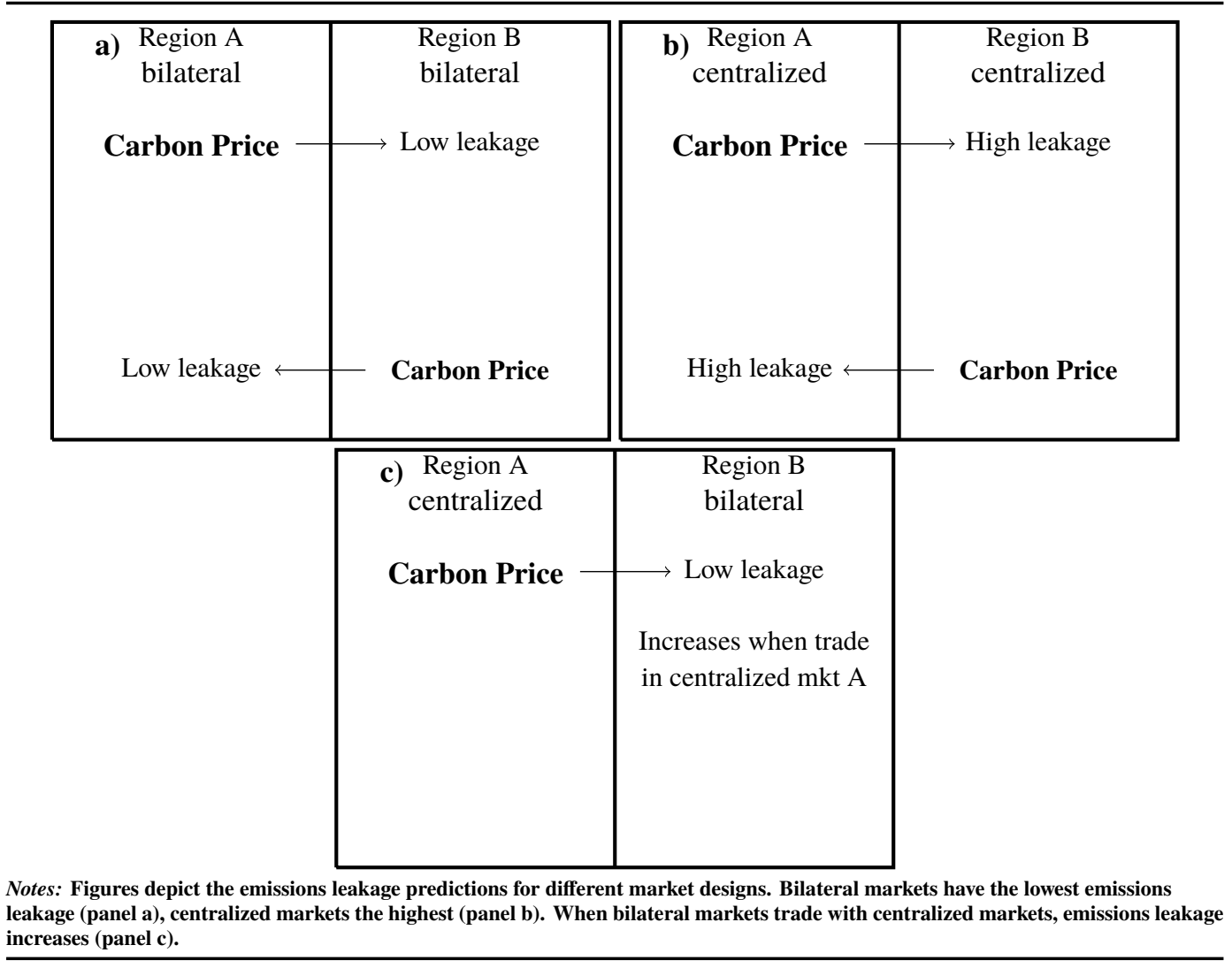

Some limitations of the model stem from simplifications made to gain tractability. The model is most appropriate for understanding short-term implications of market design across two differing regions with either limited trade or only spot market trades between them. Simplifying assumptions such as normally distributed profits, symmetric firms, no transmission constraints, ${ }^{12}$ and considering only the interior solution can be relaxed, and numerical simulations can be performed on electricity data to quantify impacts of market design relative to a counterfactual. However, as the model is Cournot, with forward contracts, the modeler must remain aware that price effects can be overstated.

\section{THEORETICAL MODEL}

The theoretical model is structured to capture key elements of electricity market design. There are two primary actors in electricity markets, power producers and electricity retailers. In some regions of the

10-local-implementation-projects-successful-go-live/ (accessed 2/22/2021).

${ }^{12}$ Transmission constraints can also affect strategic behavior and emissions leakage, see Cardell et al. (1997) and Downward (2010). 
country, non-utility producers can sell power directly to electricity retailers. Electricity trades in these regions follow more traditional market rules, ${ }^{13}$ and are overseen by independent entities known as Independent System Operators (ISOs) or Regional Transmission Organizations (RTOs) (FERC, 2015). In the model, regions with centralized auction markets are referred to as centralized markets. In other regions of the country, these actors are vertically integrated (utilities) and earn a rate-regulated rate of return. Rate-regulated utilities tend to have significant excess capacity, creating opportunities for trading amongst themselves for lower-cost power (Mansur and White, 2012). Electricity trades in these regions are primarily conducted through utility-to-utility (bilateral) transactions (FERC, 2015). In the model, regions with decentralized bilateral trading systems are referred to as bilateral markets.

In centralized markets, trades occur through the centralized auction market, where the introduction of convergence bidding instruments helped market participants explicitly manage the risk between forward contract and spot market prices, reducing producers' ability to exercise spot market power through creating arbitrage opportunities between forward market and spot market prices (Jha and Wolak, 2013). In bilateral markets, due to a lack of transparency of all available trades, forward contract and spot market prices may not necessarily converge due to a lack of conventional arbitrage mechanisms (Bessembinder and Lemmon, 2002; Mansur and White, 2012). ${ }^{14}$ For a more in-depth discussion on electricity market structure in the U.S. see Appendix A.

In the centralized market, I model strategic behavior in line with much of the existing literature, incorporating critical market details in a Cournot model with a forward contract market. Because the assumption of how the forward contract market clears affects both the extent of the forward contract market and the competitiveness of the spot market, I assume arbitrage as the forward market clearing condition in the centralized market. Arbitrage is a realistic assumption in ISO/RTO markets as convergence bidding instruments in those markets allow market participants to make virtual bids and offers in the forward contract market and liquidate those positions in the spot market (Jha and Wolak, 2013).

In modeling bilateral markets, I make specific assumptions to address key characteristics of bilateral market structure. In practice, bilateral utilities (those vertically integrated utilities operating in traditional bilateral trading systems) face a nearly inelastic demand for power from their consumers, and can meet some or all of that demand with their own power plants. To reflect this reality, I assume each bilateral utility faces an inelastic demand curve, $q_{R i, B}$, which represents demand from

\footnotetext{
${ }^{13}$ Trades in these regions are generally conducted through a multiparty electricity auction (Hausman et al., 2008).

${ }^{14}$ In bilateral markets, electricity trades can be conducted utility-to-utility, or over-the-counter (OTC) or through organized exchanges (FERC, 2015).
} 
consumers in their own region that must be served. Further, I assume that each bilateral utility receives a regulated price, $p_{B}^{r}$, for the electricity supplied to their consumers. These modeling assumptions are intended to reflect the vertically integrated structure of bilateral utilities. Because vertically integrated utilities do conduct trades through bilateral transactions, I also allow for utilities to engage in Cournot competition with other utilities (called producers, for clarity) to supply power to retail utilities. In practice, if retail utilities have upward-sloping marginal costs, this would produce a downward sloping demand for power as in my model. I reflect the opaque nature of trading in bilateral markets by clearing the forward contract and spot market without the possibility of arbitrage as a market clearing mechanism. Forward contracts are entered into when the spot market is imperfect, and there is unresolved demand and renewable resource uncertainty. Without arbitrage, forward contract prices may deviate substantially from expected future spot prices.

While a simplified version of reality, these assumptions reflect existing market structures in the U.S. and other countries. For example, in the Western electric region in the U.S., most utilities are vertically integrated and trade in bilateral markets. In California, however, the market is restructured, and operates as a centralized market. In 2014, the California ISO extended centralized spot market access to bilateral utilities across the Western electric region, facilitating centralized spot market trading across this bilateral region. Similarly, in February 2021, the Southwest Power Pool (SPP) also extended access to its centralized spot market to a different set of bilateral utilities in the Western electric region.

When emissions policies are enacted and partially overlap these different market designs (incompletely regulating emissions) climate policy outcomes can vary. Incomplete regulation in centralized markets (for example, incomplete emissions regulation within CAISO), results in different emissions leakage than incomplete emissions regulation in bilateral markets (for example, incomplete emissions regulation within the Western electric region outside of California). Further, emissions leakage changes when bilateral market participants trade with centralized market participants (for example, when Western bilateral utilities participate in CAISO's centralized spot market, and only California has an emissions regulation). The model accommodates several non-overlapping climate policies, for example, there can be incomplete or complete regulation within a centralized region or within a bilateral region, and these regulated (or unregulated) regions can trade. Simplifying assumptions can be relaxed and simulations performed for more detailed models of specific electricity markets.

The theoretical model distills this very complicated geographic network into a stylized 
representation of the fundamental features of the electricity industry that drive strategic behavior across market designs. I assume that the market takes place in only one geographic location and across two time periods, in order to develop clear and intuitive predictions of how regional climate policies affect market participants' strategic behavior and resulting emissions and emissions leakage under differing market designs.

The structure of the model is that in the first stage, the $i$ th producer in region $k$ sets the forward price, $p_{k}^{f}$, at which it is willing to sell forward contracts. Retailers then decide the quantity of forward contracts, $f_{R i, k}$, they are willing to purchase at the forward price. In the second stage, the $i$ th producer decides the quantity of electricity it will produce, $q_{G i, k}$, given the equilibrium forward contract position from the first stage. The model incorporates the effect of renewable power producers with renewable resource shocks that shift the residual demand curve. The model is solved by backward induction.

The timing of the model is that at time $t=2$, oligopolist electricity producers engage in Cournot competition in the wholesale electricity spot market. The $i$ th producer in region $k$ simultaneously selects the quantity of electricity it will produce, $q_{G i, k}$, taking as given all other producers' production levels, $q_{G j, k}$, and the forward contract it entered into at time $t=1, f_{G i, k}$, when there was uncertainty over spot market conditions because of demand uncertainty and uncertainty in intermittent renewable resource production. I make different assumptions about producer behavior in the spot market, letting it range from cooperative to non-cooperative to examine the effect of strategic behavior on market and leakage outcomes.

At time $t=1$, the $i$ th producer in region $k$ offers the forward contract price, $p_{k}^{f}$, at which it is willing to sell the forward contracts—giving its supply of forward contracts. The $i$ th retailer chooses a quantity of forward contracts, $f_{R i, k}$, to purchase from electricity producer $i$, taking as given its inelastic consumer demand, $q_{R i, k}$, all other retailers' forward contract positions, $f_{R j, k}$, and the forward price set by the producer-giving its demand for forward contracts. The market-clearing quantity of forward contracts is derived from the intersection of producers' supply of and retailers' demand for forward contracts. I assume that the forward contract market occurs after the capacity investment stage but before the electricity production stage. I denote region $k$ by $B$ if the producer/retailer is in the bilateral region, and by $C$ if the producer/retailer is in the centralized region.

Last, I extend the modeling framework to include a regional climate regulation (carbon cap-and-trade program), to determine how regional climate policies affect emissions leakage under different market designs. Like Fowlie (2009), I assume an exogenous carbon price is asymmetrically 
applied to the market. In contrast to Fowlie (2009), I assess leakage from symmetric, conventional firms under different market designs, and explicitly consider how trading electricity across those market designs exacerbates or ameliorates emissions leakage.

\subsection{Centralized market design: one-stage model}

In this section, I introduce the one-stage model, in which demand and renewable resource shocks are realized and $N_{C}$ oligopoly producers in region $C$ engage in Cournot competition to clear the spot market, determining spot price, quantity of electricity, and quantity of emissions produced. The $i$ th producer's objective function is to maximize profit:

$$
\max _{q_{G i, C}} \pi_{G i, C}=p_{C}^{s}\left(Q_{G, C}, \tilde{Q}_{C}, \theta_{C}\right)\left(q_{G i, C}\right)-c_{i}\left(q_{G i, C}\right)+d_{i} \tau\left(A_{i}-e_{i} q_{G i, C}\right)
$$

The (inverse) residual demand curve facing conventional producers is $p_{C}^{s}=\left(a_{C}-\tilde{Q}_{C}+\theta_{C}-q_{G i, C}-\right.$ $\left.\sum_{j \neq i}^{N_{C}} q_{G j, C}\right)$. I let $\tilde{Q}_{C}$ represent stochastic renewables shocks that shift the residual demand curve, where $\tilde{Q}_{C}$ is the realized value of the renewable production shock, drawn from a normal distribution with mean $\mu$ and variance $\sigma_{\tilde{Q}_{C}}^{2}$ with support $(-\infty, \infty)$. I assume that this distribution is common knowledge, as all agents know the renewable capacity in the system and the distribution of weather. ${ }^{15}$ I also let $\theta_{C}$ represent stochastic demand shocks from industrial customers, or weather shocks affecting end-use customers, that also shift the residual demand curve above or below its baseload level. I assume that demand shocks are drawn from a normal distribution with mean 0 and variance $\sigma_{\theta}^{2}$, and that the distribution is common knowledge among electricity producers and retailers.

I assume that producers have a constant marginal cost of electricity production, $c_{i}$, where $c_{i}>0$. Although producers are symmetric in my framework, I do identify the costs attributed to each producer, as they affect emissions leakage. Following Fowlie (2009) I assume that there is one pollutant from conventional electricity production and that the emissions of the $i$ th firm for conventional production are proportional to output: $e_{i}=e_{i} q_{G i, C} \cdot d_{i}=1$ for firms that are subject to regional climate regulations. $A_{i}$ denotes the exogenous allocation of emissions permits. Regulated firms are assumed to be price-takers in the emissions permit market, where the exogenous price of the permit is $\tau$.

All other costs, such as investment in capacity and capital costs for renewable and conventional

\footnotetext{
${ }^{15}$ I model variable renewable energy production as shocks that shift residual demand, because renewable output is not controllable by the electricity producer in the spot market. Curtailment (shut-down) decisions for renewable producers are not considered in this model.
} 
resources, will be ignored for the short-run model.

The first-order conditions for profit maximization are

$$
\frac{\partial \pi_{G i, C}}{\partial q_{G i, C}}=p_{C}^{s}\left(Q_{G, C}, \tilde{Q}_{C}, \theta_{C}\right)+p_{C}^{s^{\prime}}\left(Q_{G, C}, \tilde{Q}_{C}, \theta_{C}\right) q_{G i, C}-c_{i}-\tau d_{i} e_{i}=0, \quad i=1, \ldots, N_{C}
$$

After substituting for $p_{C}^{s}$ and solving, the Cournot-Nash equilibrium quantity produced by producer $i$ is

$$
q_{G i, C}=\frac{1}{N_{C}+1}\left\{a_{C}-\tilde{Q}_{C}+\theta_{C}-N_{C}\left(c_{i}+\tau d_{i} e_{i}\right)+\sum_{j \neq i}^{N_{C}}\left(c_{j}+\tau d_{j} e_{j}\right)\right\},
$$

and rival producers are the same by symmetry. In equilibrium, $\sum_{i=1}^{N_{C}} q_{G i, C}=Q_{G, C}$. Throughout the model I highlight equilibrium quantities for their leakage implications, full derivations of spot market conditions, including equilibrium prices and quantities are provided in Appendix D.

\subsection{Centralized market design: two-stage model}

In this section, a forward contract market is added to the model. At time $t=2$, demand and renewables shocks are realized and the spot market must clear. $N_{C}$ oligopoly producers engage in Cournot competition in region $C$, taking as given the forward contract positions from $t=1$, to determine the final spot price, quantity, and emissions levels. The $i$ th producer's objective function is to maximize profit:

$$
\begin{aligned}
\max _{q_{G i, C}} \pi_{G i, C}=p_{C}^{s}\left(Q_{G, C}, \tilde{Q}_{C}, \theta_{C}\right)\left(q_{G i, C}-f_{G i, C}\right)-c_{i}\left(q_{G i, C}\right. & \left.-f_{G i, C}\right)-c_{i} \gamma f_{G i, C} \\
& +d_{i} \tau\left(A_{i}-e_{i} q_{G i, C}\right)+p_{C}^{f} f_{G i, C} .
\end{aligned}
$$

If the $i$ th producer committed to sell $f_{G i, C}$ in the forward market, the producer will only sell $\left(q_{G i, C}-f_{G i, C}\right)$ in the spot market.

To capture the possibility that committing to a production level in the forward contract market may change the costs of adapting to shocks in the spot market, I include an efficiency parameter $\gamma \in(0,1)$ to reflect the difference in efficiency of committing a producer in the forward contracts market vs. the spot market. This parameter $(\gamma)$ reduces the cost of delivery and increases efficiency in the market. ${ }^{16}$ The first term, $c_{i}\left(q_{G i, C}-f_{G i, C}\right)$, is the cost of spot market electricity production and is

\footnotetext{
${ }^{16}$ Although the forward contract positions are financial transactions, they are not economically costless, because power plants require start-up time and must be brought on line well in advance of actual production (Bushnell and Wolak, 2006). It is more costly for most plants to produce electricity with limited start-up time.
} 
net of the forward contract commitment. The second term, $c_{i} \gamma f_{G i, C}$, is the total cost of electricity production committed to in the forward market.

The first-order conditions for profit maximization are

$$
\frac{\partial \pi_{G i, C}}{\partial q_{G i, C}}=p_{C}^{s}\left(Q_{G, C}, \tilde{Q}_{C}, \theta_{C}\right)+p_{C}^{s^{\prime}}\left(Q_{G, C}, \tilde{Q}_{C}, \theta_{C}\right)\left(q_{G i, C}-f_{G i, C}\right)-c_{i}-\tau d_{i} e_{i}=0, \quad i=1, \ldots, N_{C}
$$

After substituting for $p_{C}^{s}$ and solving, the Cournot-Nash equilibrium quantity produced by producer $i$ is

$$
q_{G i, C}^{*}=\frac{1}{N_{C}+1}\left\{a_{C}-\tilde{Q}_{C}+\theta_{C}-N_{C}\left(c_{i}+\tau d_{i} e_{i}\right)+\sum_{j \neq i}^{N_{C}}\left(c_{j}+\tau d_{j} e_{j}\right)+f_{G i, C}\right\}
$$

and rival producers are the same by symmetry. In equilibrium, $\sum_{i=1}^{N_{C}} q_{G i, C}^{*}=Q_{G, C}^{*}$. Full derivations of spot market conditions and outcomes are provided in Appendix D. Intuition regarding spot market outcomes is provided in the next section, after determination of the equilibrium forward market position.

\subsubsection{Centralized forward contract market}

Having solved for how producers behave optimally in the spot market, the next step is to backward induct to the forward market. The $i$ th retailer's expected profits are

$$
\mathbb{E}\left(\pi_{R i, C}\right)=q_{R i, C}\left[p_{C}^{r}-\mathbb{E}\left(p_{C}^{s}\right)\right]+f_{R i, C}\left[\mathbb{E}\left(p_{C}^{s}\right)-p_{C}^{f}\right],
$$

which it maximizes from selling a fixed quantity of electricity to final customers, $q_{R i, C}$, at the regulated retail price, $p_{C}^{r},{ }^{17}$ less the expected cost of purchasing the electricity on the spot market, $\mathbb{E}\left(p_{C}^{s}\right)$. The $i$ th retailer's expected spot market profits are given by the first term in the expression for the expected profits, $q_{R i, C}\left[p_{C}^{r}-\mathbb{E}\left(p_{C}^{s}\right)\right]$. The retailer also arbitrages its expected profits by buying electricity on the forward contract market. The retailer's arbitrage profits are given by the second term in the expression for the expected profits, $f_{R i, C}\left[\mathbb{E}\left(p_{C}^{s}\right)-p_{C}^{f}\right]$, which takes the price in the forward contract market set by the producer, $p_{C}^{f}$, as given.

I assume that the $i$ th retailer is risk averse, to reflect the risk asymmetry problem that retailers face in real-world wholesale electricity markets. Retailers are required to sell at regulated retail rates in most states, creating an inelastic demand for electricity. Electricity retailers are captive on the spot

\footnotetext{
${ }^{17}$ The retail electric price, $p_{C}^{r}$, is assumed to be fixed for this model to reflect that retail electricity prices are set by the regulator and are plausibly exogenous in the short-term.
} 
market, at times having to pay high spot market prices to fulfill their supply obligations. ${ }^{18}$ Retailers, perceiving the possibility for producers to exercise market power in the spot market, may even be willing to pay a price premium, as forward contracts limit producers' ability to exercise market power (Allaz and Vila, 1993; Allaz, 1992; Powell, 1993). Producers, on the other hand, are not required to produce below cost, resulting in risk asymmetry for retailers on the spot market. ${ }^{19}$

The risk-averse retailer's objective is to maximize its expected value by choosing the forward contract quantity, $f_{R i, C}$, that maximizes its expected profits while minimizing its CVaR. The value function for the retailer is

$$
V_{R i, C}=\mathbb{E}\left(\pi_{R i, C}\right)-\phi_{R i, C} \mathrm{CVaR}_{\alpha}\left(-\pi_{R i, C}\right)
$$

where $\phi_{R i, C}$ is a preference parameter for risk avoidance (Di Maria et al., 2016) that represents the $i$ th retailer's risk aversion. The confidence level of the VaR and CVaR is $\alpha{ }^{20}$ As shown in Appendix E, assuming that profits follow a normal distribution, the $i$ th retailer's value function is

$$
\begin{aligned}
\max _{f_{R i, C}} V_{R i, C}=\left(1+\phi_{R i, C}\right)\left\{q_{R i, C}\left[p_{C}^{r}-\mathbb{E}\left(p_{C}^{s}\right)\right]+f_{R i, C}\left[\mathbb{E}\left(p_{C}^{s}\right)-p_{C}^{f}\right]\right\} & \\
& -\frac{1}{N_{C}+1} \phi_{R i, C} b(\alpha) \sigma_{\theta, \tilde{Q}}\left(q_{R i, C}-f_{R i, C}\right),
\end{aligned}
$$

where the first-order conditions for a maximum are

$$
\begin{aligned}
\frac{\partial V_{R i, C}}{\partial f_{R i, C}}=\left(1+\phi_{R i, C}\right)\left\{-q_{R i, C}\left(\frac{\partial \mathbb{E}\left(p_{C}^{s}\right)}{\partial f_{R i, C}}\right)+f_{R i, C}\left(\frac{\partial \mathbb{E}\left(p_{C}^{s}\right)}{\partial f_{R i, C}}\right)+\left[\mathbb{E}\left(p_{C}^{s}\right)-p_{C}^{f}\right]\right\} & \\
& +\frac{1}{N_{C}+1} \phi_{R i, C} b(\alpha) \sigma_{\theta, \tilde{Q}}=0, \quad i=1, \ldots, N_{C}
\end{aligned}
$$

The first-order condition is solved to find the $i$ th retailer's demand for forward contracts:

$$
f_{R i, C}=q_{R i, C}-\frac{\left(\phi_{R i, C}+1\right)\left[\mathbb{E}\left(p_{C}^{s}\right)-p_{C}^{f}\right]+\frac{1}{N_{C}+1} \phi_{R i, C} b(\alpha) \sigma_{\theta, \tilde{Q}}}{\frac{\partial p_{C}^{s}}{\partial f_{R i, C}}\left(\phi_{R i, C}+1\right)}
$$

The first component of the forward contract position, $q_{R i, C}$, is the retailer's consumer electric demand

\footnotetext{
${ }^{18}$ Note that load serving entities may have hedging strategies to address being held captive on the spot market as part of the regulatory compact, I assume these entities can be held captive on the spot market as a simplifying assumption.

${ }^{19}$ The assumption of risk-averse retailers can also be modified by assuming risk-neutrality if, for example, particular retailers in a market are not risk-averse.

${ }^{20}$ Value at Risk (VaR) is a measure of market risk that gives the maximum losses that can be expected with a certain level of confidence, specified by a probability level $\alpha$ in $(0,1)$. CVaR gives the conditional expectation of the loss that is greater than or equal to the VaR, that is the tail VaR (Rockafellar and Uryasev, 2000).
} 
that must be met-the strategic component. Noting that the partial derivative $\partial p_{C}^{s} / \partial f_{R i, C}<0$, the second component demonstrates that the retailer increases its optimal quantity of forward contracts to hedge against price risk due to differences in forward and spot prices - the risk-hedging component. Risk aversion, $\phi_{R i, C}$, further increases the risk-hedging component. The difference in the forward contract position that can be derived from differences in forward and spot market prices with riskaverse retailers is an important element of this model, as it is explicitly affected by the assumption of arbitrage_-an assumption that varies across different market designs.

Participation of outside financial speculators in a centralized market forces convergence in the forward market-clearing price and the expected spot market-clearing price. Substituting the arbitrage forward market-clearing condition, $p_{C}^{f}=\mathbb{E}\left(p_{C}^{s}\right)$, into equation (3) and noting that $\phi_{R i, C}=0$ for at least one risk-neutral participant, ${ }^{21}$ the equilibrium forward position for the $i$ th retailer in a centralized market is $f_{R i, C}^{*}=q_{R i, C}^{*}$. Rival retailers' positions are the same by symmetry. The total forward contract demand is equal to the retailers' inelastic consumer demand:

$$
\sum_{i=1}^{N_{C}} f_{R i, C}^{*}=\sum_{i=1}^{N_{C}} q_{R i, C}^{*}=Q_{R, C}^{*}
$$

PROPOSITION 1: Non-cooperative producer behavior and participation of outside financial speculators in a centralized electricity market brings convergence in the spot market price and forward contract market price. The optimal forward contract hedge of the retailer is equal to its anticipated electricity demand and is unaffected by the emissions permit price, $\tau$. In a centralized market, electricity retailers hedge the full amount of their inelastic consumer demand.

In the centralized market model, the $i$ th producer's forward contract supply, $p_{C}^{f}$, is defined by the arbitrage condition: $p_{C}^{f}=E\left(p_{C}^{s}\right){ }^{22}$ Substituting the equilibrium forward contract quantity in equation (4) into the inverse demand to find the equilibrium spot price, the equilibrium forward contract market price is then

$$
p_{C}^{f *}=E\left(p_{C}^{s *}\right)=\frac{a_{C}-\mu_{C}+\sum_{i=1}^{N_{C}}\left(c_{i}+\tau d_{i} e_{i}\right)-Q_{R, C}^{*}}{N_{C}+1}
$$

\footnotetext{
${ }^{21}$ This assumption requires that there is at least one risk-neutral participant in the centralized market. If participants were risk averse, retailers would increase the optimal level of their forward contract hedge by $\left(\frac{\phi_{R i, C} /}{\left(1+\phi_{R i, C}\right)}\right) b(\alpha) \sigma_{\theta, \tilde{Q}}$, which would lower the equilibrium forward and spot prices. This assumption can result in risk asymmetry across markets, as pointed out by an anonymous reviewer, but this assumption can be modified for either centralized or bilateral markets.

${ }^{22}$ The $i$ th producer's first-stage profits are defined as $\mathbb{E}\left[\pi_{G i, C}\right]=\mathbb{E}\left[\left(p_{C}^{f}-p_{C}^{s}\right) f_{G i, C}+p_{C}^{s} q_{G i, C}-c_{i}\left(q_{G i, C}-\right.\right.$ $\left.f_{G i, C}\right)-c_{i} \gamma f_{G i, C}+\tau\left(A i-d_{i} e_{i}\left(q_{G i, C}\right)\right]$, where $p_{C}^{f}$ is determined by the arbitrage condition, and $f_{G i, C}=f_{R i, C}$ in equilibrium.
} 
PROPOSITION 2: Price arbitrage influences the extent of the forward contract market and equates forward contract and spot market prices. The positive forward contract position, derived from retailers hedging the full amount of their inelastic consumer demand, reduces the expected spot and forward contract market prices, evidencing the pro-competitive effect of the forward contract market. The costs of the emissions permit increase the forward market-clearing price.

Substituting the equilibrium forward contract quantity in equation (4) into producer $i$ 's quantity produced in equation (2), the optimal quantity of electricity produced in the spot market by the $i$ th producer is

$$
q_{G i, C}^{* *}=\frac{1}{N_{C}+1}\left\{a_{C}-\tilde{Q}_{C}+\theta_{C}-N\left(c_{i}+\tau d_{i} e_{i}\right)+\sum_{j \neq i}^{N_{C}}\left(c_{j}+\tau d_{j} e_{j}\right)+q_{R i, C}^{*}\right\},
$$

and in the aggregate, $\sum_{i=1}^{N_{C}} q_{G i, C}^{* *}=Q_{G, C}^{* *}$.

PROPOSITION 3: The existence of a forward contract market increases the competitiveness of the spot market through increasing conventional electricity production levels above what they would be in the absence of a forward contract market, which will have emissions leakage implications.

The increase in the quantity of electricity produced from the strictly positive forward contract market position serves to make the centralized market more competitive, compared to the results of the one-stage model in Section 2.1, which affects emissions leakage. Renewable electricity has the opposite effect. It reduces the quantity of conventional electricity produced by reducing the residual demand that producers face.

\subsection{Bilateral market design: two-stage model}

Bilateral utilities can participate in regional exchanges or power pools that facilitate trades. In my model, I represent the bilateral spot market similar to the centralized spot market. But because arbitrage cannot be assumed as a market-clearing condition for the bilateral market, I model retailers as buyers in the forward contract market. In practice, some utilities have excess capacity and offer power for sale in the wholesale market. In this case, a given utility may act like the retailers or the producers in my model at any given point in time. For simplicity, I separate these roles in the model and assume they are fixed. My stylized approach involves $N_{B}$ bilateral utilities. I omit the one-stage model for the bilateral spot market as first-order conditions are equivalent to those found in the centralized market. 


\subsubsection{Bilateral spot market}

At time $t=2$, the $i$ th bilateral producer's objective in the bilateral spot market is to maximize its profits from choosing how much electricity to sell to the bilateral market, $q_{G i, B}$, taking as given the forward contract it has entered into, $f_{G i, B}$, at time $t=1$ :

$$
\begin{aligned}
\max _{q_{G i, B}} \pi_{G i, B}=p_{B}^{s}\left(Q_{B}, \tilde{Q}_{B}, \theta_{B}\right)\left(q_{G i, B}\right. & \left.-f_{G i, B}\right)+p_{B}^{r} q_{R i, B}-c_{i}\left(q_{G i, B}-f_{G i, B}+q_{R i, B}\right) \\
& -c_{i} \gamma\left(f_{G i, B}\right)+\tau\left(A_{i}-d_{i} e_{i} q_{G i, B}-d_{i} e_{i} q_{R i, B}\right)+p_{B}^{f} f_{G i, B} .
\end{aligned}
$$

I assume that the $i$ th bilateral producer faces an inelastic demand curve from consumers in its own region, $q_{R i, B}$. I model the inverse demand curve as an inelastic shock, where $q_{R i, B}=\left(a_{i}-\rho \tilde{Q}_{i}+\eta \theta_{i}\right)$, $\rho$ adjusts for the size of the renewable resource shock faced by the $i$ th producer, and $\eta$ is the size of the regional demand shock the producer experiences in its own region. I assume that the $i$ th producer receives a fixed price for its regional electricity production, where $p_{B}^{r}$ is the fixed price set by the regulator. In addition to servicing its own inelastic regional demand, I assume that the $i$ th producer and its rival producers engage in Cournot competition to supply power to retailers' in the bilateral spot market, where retailers spot market demand is $p_{B}^{s}=\left(a_{B}-\tilde{Q}_{B}+\theta_{B}-q_{G i, B}-\sum_{j \neq i}^{N_{B}} q_{G j, B}\right)$.

The first-order conditions for profit maximization are

$$
\frac{\partial \pi_{G i, B}}{\partial q_{G i, B}}=p_{B}^{s}\left(Q_{B}, \tilde{Q}_{B}, \theta_{B}\right)+p_{B}^{s^{\prime}}\left(Q_{B}, \tilde{Q}_{B}, \theta_{B}\right)\left(q_{G i, B}-f_{G i, B}\right)-c_{i}-\tau d_{i} e_{i}=0, \quad i=1, \ldots, N_{B}
$$

The Cournot-Nash equilibrium quantity produced by producer $i$ is

$$
q_{G i, B}^{*}=\frac{1}{N_{B}+1}\left\{a_{B}-\tilde{Q}_{B}+\theta_{B}-N_{B}\left(c_{i}+\tau d_{i} e_{i}\right)+\sum_{j \neq i}^{N_{B}}\left(c_{j}+\tau d_{j} e_{j}\right)+f_{G i, B}\right\}
$$

and the rival producers are the same by symmetry. In equilibrium, $\sum_{i=1}^{N_{B}} q_{G i, B}^{*}=Q_{B}^{*}$. Full derivations of bilateral spot market conditions and outcomes are provided in Appendix D. Intuition regarding spot market outcomes is provided in the next section, following the determination of the equilibrium forward contract market position. 


\subsubsection{Bilateral forward contract market}

At time $t=1$ the $i$ th bilateral retailer faces the same profit-maximizing decision as the retailers in the centralized markets, so that the retailer's demand for forward contracts can be represented by equation (3). However, because of a lack of financial speculators in the regional bilateral markets, the risk-hedging component of the forward contract position can exist on account of price risk. This assumption — that price risk exists in bilateral markets—is made to reflect the reality that in bilateral markets, financial instruments such as convergence bidding instruments are not available. The lack of readily available financial instruments limits the participation of purely financial speculators. Provided that retailers are risk averse, discrepancies between forward contract and spot market prices can exist, and my model allows for this possibility.

Substituting the pro-competitive effect of the forward contract position on the spot market price $\left(\partial \mathbb{E}\left(p_{B}^{s}\right) / \partial f_{R i, B}\right)$ into equation (3) gives the retailer's demand for forward contracts in the forward market:

$$
f_{R i, B}=q_{R i, B}+\left(N_{B}+1\right)\left[\mathbb{E}\left(p_{B}^{s}\right)-p_{B}^{f}\right]+\frac{\phi_{R i, B}}{1+\phi_{R i, B}} b(\alpha) \sigma_{\theta, \tilde{Q}}
$$

In contrast to the centralized market, when there is price risk, $\mathbb{E}\left(p_{B}^{s}\right) \neq p_{B}^{f}$, the retailers increase their forward contract position not only as their inelastic consumer demand increases, $q_{R i, B}$, but also as their risk aversion, $\phi_{R i, B}$, and variability of profits increases, $\sigma_{\theta, \tilde{Q}}$, making their demand more inelastic.

Substituting the expression for $\mathbb{E}\left(p_{B}^{s}\right)$ and noting that retailers are symmetric, $f_{R i, B}=f_{-R i, B}$, the Cournot-Nash equilibrium quantity of forward contracts demanded by each retailer is

$$
f_{R i, B}^{*}=\frac{1}{N_{B}+1}\left\{q_{R i, B}+\frac{\phi_{R i, B}}{1+\phi_{R i, B}} b(\alpha) \sigma_{\theta, \tilde{Q}}+\left(a_{B}-\mu_{B}+\sum_{i=1}^{N_{B}}\left(c_{i}+\tau d_{i} e_{i}\right)\right)-\left(N_{B}+1\right) p_{B}^{f}\right\} .
$$

The forward contract position reflects that variability of profits, risk aversion, and factors such as spot market production costs can make retailers' forward contract positions more inelastic. Demand for forward contracts is decreasing in the forward contract's price, $p_{B}^{f}$.

In this model, bilateral producers are the price-setters in the forward contract market, giving them the market power. This assumption is made to reflect the risk asymmetry prevalent in electricity markets. Retailers are captive on the spot market, making it in producers' interest to wait and trade in the spot market, where there is the possibility that they could exercise horizontal market power (which 
is difficult to detect) (Hausman et al., 2008). This holdup problem can spill over into the forward contracting market, where producers do not have an incentive to sell electricity forward unless they receive a price premium.

At time $t=1$, the $i$ th bilateral producer's objective is to set the price, $p_{B}^{f}$, that will maximize its expected profits from the bilateral forward contract market while taking into account the effect the forward contract price it sets will have on its expected spot market profits:

$$
\begin{array}{r}
\max _{p_{B}^{f}} \mathbb{E}\left[\pi_{G i, B}\right]=\mathbb{E}\left[\left(p_{B}^{f}-p_{B}^{s}\right) f_{G i, B}+p_{B}^{s} q_{G i, B}+p_{B}^{r} q_{R i, B}-c_{i}\left(q_{G i, B}-f_{G i, B}+q_{R i, B}\right)\right. \\
\left.-c_{i} \gamma f_{G i, B}+\tau\left(A i-d_{i} e_{i}\left(q_{G i, B}+q_{R i, B}\right)\right)\right],
\end{array}
$$

where $q_{G i, B}\left(f_{G i, B}\right), p_{B}^{s}\left(f_{G i, B}\right)$, and $f_{G i, B}\left(p_{B}^{f}\right)$ are from equations (7), the bilateral spot price, and (9), respectively.

The first-order condition can be rewritten as

$$
\begin{aligned}
-\left[p_{B}^{f}-\mathbb{E}\left(p_{B}^{s}\right)+c_{i}(1-\gamma)\right] \frac{\partial f_{G i, B}}{\partial p_{B}^{f}}-\left[\mathbb{E}\left(p_{B}^{s}\right)-\left(c_{i}+\tau d_{i} e_{i}\right)\right] \frac{\partial \mathbb{E}\left(q_{G i, B}\right)}{\partial p_{B}^{f}} & \left.=f_{G i, B}+\left(\mathbb{E}\left(q_{G i, B}\right)-f_{G i, B}\right)\right) \frac{\partial \mathbb{E}\left(p_{B}^{s}\right)}{\partial p_{B}^{f}} .
\end{aligned}
$$

Substituting the expressions for the partial derivatives and simplifying provides the bilateral forward contract price premium that the $i$ th bilateral producer will charge for its supply of forward contracts. ${ }^{23}$

$$
p_{B}^{f}-\mathbb{E}\left[p_{B}^{s}\right]=\frac{1}{\left(N_{B}+1\right)^{2}}\left\{\left(3 N_{B}+1\right) f_{G i, B}-\left(N_{B}+1\right)^{2} c_{i}(1-\gamma)+\left(N_{B}-1\right)\left(a_{B}-\mu_{B}-\left(c_{i}+\tau d_{i} e_{i}\right)\right\}\right.
$$

Noting that in equilibrium, producers' supply will equal retailers' demand for forward contracts, producers can charge a price premium as demand for forward contracts, $f_{G i, B}$, becomes more inelastic. Producers will also charge a higher price premium if expected residual demand exceeds spot market production costs. All other bilateral producers will charge the same price premium by symmetry.

\footnotetext{
${ }^{23}$ Note that in solving the model, I follow Powell (1993) and make the assumption that producers cooperate in the forward contract market, which is equivalent to considering the aggregate effect of the producers' forward contract prices on the spot market price. This assumption is being made because truly non-competitive behavior in the forward contract market leads to the competitive outcome, as firms undercut each other to gain a larger market share but have no incentive to accept a price below the expected spot price (Powell, 1993). This feature of the model could be remediated by incorporating convex costs, however costs are assumed to be linear as a simplifying assumption.
} 
PROPOSITION 4: As the bilateral retailers' demand for forward contracts becomes more inelastic, the bilateral producers are able to seek a higher price premium. The forward contract price premium also increases if the expected residual demand is expected to exceed a producer's incremental costs for spot market production, as residual demand in the spot market allows producers to exercise market power and drive up the spot market price above their costs.

As shown in the Appendix, the equilibrium quantity of bilateral forward contracts demanded at the bilateral forward contract price can be found by aggregating individual supply of forward contracts from equation (10), and equating it with the aggregated individual demand for forward contracts from equation (9). For each individual retailer, equilibrium demand for forward contracts is

$$
\begin{aligned}
f_{R i, B}^{* *} & =\frac{1}{2\left(2 N_{B}+1\right)}\left\{\left(N_{B}+1\right)\left(q_{R i, B}+\phi_{R i, B} b(\alpha) \sigma_{\theta, \tilde{Q}}\right)-\left(N_{B}-1\right)\left(a_{B}-\mu_{B}\right)\right\} \\
& +\frac{1}{2\left(2 N_{B}+1\right)}\left\{\left(N_{B}-1\right)\left(N_{B}\left(c_{i}+\tau d_{i} e_{i}\right)-\sum_{j \neq i}^{N_{B}}\left(c_{j}+\tau d_{j} e_{j}\right)\right)+\left(N_{B}+1\right)^{2} c_{i}(1-\gamma)\right\} .
\end{aligned}
$$

I will examine the forward contract market under a few different scenarios to reflect real-world bilateral market possibilities. The extent of retail competition varies by state, where 13 states plus Washington, D.C. have fully restructured their electricity markets allowing for retail competition (Rose et al., 2020), in other states, varied degrees of retailer competition exist.

\subsubsection{Non-Cooperative Behavior in Forward and Spot Markets}

If producers were to behave truly non-cooperatively in the forward contract and spot market, under certainty, the forward contract price would equal the expected spot price and bilateral retailers would hedge the full amount of their inelastic consumer demand (Powell, 1993). To see this scenario in my model, modify the bilateral retailer forward contract position in equation (8) for the case of no price risk, $\mathbb{E}\left(p_{B}^{s}\right)=p_{B}^{f}$, and no renewable resource or demand uncertainty, $\sigma_{\theta, \tilde{Q}}=0$. The result is

$$
f_{R i, B}=q_{R i, B},
$$

which is the same outcome as in the centralized market. This scenario most closely approximates the degree of retail competition in fully restructured electricity markets.

However, in real-world electricity markets, producers may be able to charge a price premium for forward contracts (Hausman et al., 2008). I will consider two scenarios in which this could occur. 
The first is if producers behave cooperatively in the bilateral spot market and forward contract market. The second is if producers behave non-cooperatively in the spot market but cooperatively in the forward contract market.

\subsubsection{Cooperative Behavior in Forward and Spot Markets}

Behaving cooperatively in the spot and forward contract markets is equivalent to the monopoly outcome, or $N_{B}=1$. This scenario is appropriate if retailers act as monopsonists within their service territories. As shown in the Appendix, aggregating equation (11) and substituting $N_{B}=1$ gives the equilibrium forward contract position for the cooperative retailers:

$$
F_{R, B}=\frac{1}{3}\left\{q_{R, B}+\frac{\phi}{1+\phi} b(\alpha) \sigma_{\theta, \tilde{Q}}+2 c(1-\gamma)\right\} .
$$

Compared to the centralized market, the bilateral retailers' forward contract positions will generally be less than those of retailers in the centralized market, as they do not hedge the full amount of their inelastic consumer demand. The bilateral forward contract position increases with risk aversion and the incremental cost of spot market production, so results will depend on the underlying parameters of the markets in question. Substituting $N_{B}=1$ into equation (10), gives the cooperative producer's price premium:

$$
p^{f}-\mathbb{E}\left[p^{s}\right]=f_{R, B}-c(1-\gamma)
$$

The spot price premium is increasing in the forward contract demand, but decreasing in the incremental cost by which spot market production exceeds the cost of generators committed in the forward contract market. Notably, if producers behave cooperatively in the forward contract and spot markets, emissions prices do not factor into the forward contracting decision beyond the spot price premium, which will have emissions leakage implications.

\subsubsection{Non-Cooperative Behavior in the Spot Market, Cooperative Behavior in the Forward Market}

Behaving non-cooperatively in the spot market but cooperatively in the forward contracts market can be shown with two retailers, $N_{B}=2$. This scenario allows for the possibility that retailers are neither perfectly competitive nor monopsonists in their service territories. The bilateral retailers' equilibrium 
forward contracts hedge is

$$
F_{R, B}=\frac{3}{5}\left\{q_{R, B}+\frac{\phi}{1+\phi} b(\alpha) \sigma_{\theta, \tilde{Q}}+3 c(1-\gamma)\right\}-\frac{1}{5}\{a-\mu-(c+\tau d e)\}
$$

which will generally result in a smaller forward contract position than in the cooperative outcome, and may possibly even be negative, depending on the underlying parameters of the model.

Substituting $N_{B}=2$ into the equation (10) gives the price premium for each bilateral producer of

$$
p^{f}-\mathbb{E}\left[p^{s}\right]=\frac{7}{9} f_{R, B}+\frac{1}{9}(a-\mu-(c+\tau d e))-c(1-\gamma)
$$

The actual amounts of the equilibrium forward contracts and price premium charged will depend on underlying parameters of the specific electricity market under consideration.

PROPOSITION 5: In the bilateral forward contract market, the optimal forward contract position for retailers will generally be less than in the centralized market, as the retailer will generally hedge less than the full amount of its consumer demand. Risk aversion increases the forward contract hedge, regardless of producer behavior, and forward contract price premiums increase as retailer demand for forward contracts becomes more inelastic. Cooperative behavior among producers in forward contract and spot markets generally increases the retailers' forward contract hedge, as retailers have more of an incentive to purchase forward contracts in order to mitigate producers' ability to exercise market power in this scenario.

Finally, equilibrium output produced in the bilateral market with the equilibrium forward contract position is found by substituting the equilibrium quantity of forward contracts traded in equation (11) into the $i$ th producer's spot market output in equation (7),

$$
\begin{aligned}
q_{G i, B}^{* *}=\frac{1}{2\left(2 N_{B}+1\right)}\left\{3\left(a_{B}-\tilde{Q}_{B}+\theta_{B}\right)+q_{R i, B}+\frac{\phi_{R i, B}}{1+\phi_{R i, B}} b(\alpha) \sigma_{\theta, \tilde{Q}}\right\} \\
+\frac{1}{2\left(2 N_{B}+1\right)}\left\{\left(N_{B}+1\right) c_{i}(1-\gamma)-3 N_{B}\left(c_{i}+\tau d_{i} e_{i}\right)+3 \sum_{j \neq i}^{N_{B}}\left(c_{j}+\tau d_{j} e_{j}\right)\right\},
\end{aligned}
$$

and total bilateral production is $\sum_{i=1}^{N_{B}} q_{G i, B}^{* *}=Q_{G, B}^{* *}$.

PROPOSITION 6: The existence of the bilateral forward contract market acts to limit bilateral producers' market power by increasing conventional electricity output above what it would be without a forward contract market, provided that the forward contract position is positive. As equilibrium output differs across market designs, there will be emissions leakage implications. 


\subsection{Emissions Leakage}

\subsubsection{Case 1. Emissions leakage in the centralized market under incomplete environmental regulation}

For the first case of emissions leakage, I assess how incomplete regulation—regulation that is applied to only some producers within a region—can affect emissions leakage for electricity producers operating under the centralized market design. Similar to Fowlie (2009), in my emissions leakage calculations I compare the emissions of producer $i$ when producer $j$ is regulated, to the emissions of producer $i$ when producer $j$ is unregulated. Emissions leakage is then the additional emissions generated by the unregulated producer under incomplete regulation. I define leakage in the centralized market as

$$
L=\sum_{i=1}\left(1-d_{i}\right) e_{i}\left(q_{G i, C}^{* *, R E G}-q_{G i, C}^{* *, 0}\right),
$$

where $\sum_{i=1}\left(1-d_{i}\right)$ is the number of unregulated producers The optimal quantity of electricity generated by the $i$ th producer when the $j$ th producer is not regulated is $q_{G i, C}^{* *, 0}$, and the optimal quantity of electricity produced by the $i$ th producer under incomplete regulation (when the $j$ th producer is regulated) is $q_{G i, C}^{* *, R E G}$. Leakage is then the additional emissions generated by the $i$ th unregulated producer.

As shown in Appendix G, summing across producers, where the number of regulated producers is $\sum_{j \neq i} d_{j}=N_{1}$, and the number of unregulated producers is $\sum_{i=1}\left(1-d_{i}\right)=N_{0}$, leakage can be written as

$$
L=N_{0} \bar{e}_{0} \tau\left(\frac{N_{1} \bar{e}_{1}}{N_{C}+1}\right)
$$

For example, the case of one unregulated producer, $N_{0}=1$, and one regulated producer, $N_{1}=1$, provides the duopoly leakage condition for the centralized market:

$$
L=\tau\left(\frac{\bar{e}_{0} \bar{e}_{1}}{3}\right)
$$

The effect of incomplete regulation within the centralized market design is that unregulated producers will have higher emissions by a factor of $\frac{\bar{e}_{1}}{3}$ than regulated producers, and emissions leakage is positive.

If, for example, the centralized market instead consists of four producers, two of which are 
regulated, the leakage condition due to incomplete regulation would be

$$
L=\tau\left(\frac{4 \bar{e}_{0} \bar{e}_{1}}{5}\right)
$$

For symmetric producers, emissions leakage from incomplete regulation increases because the market becomes more competitive and producers respond more to an incremental increase in production costs from the permit price. I will return to this example in Case 2 to compare emissions leakage across market designs.

\subsubsection{Case 2. Emissions leakage in the bilateral market under incomplete environmental regulation}

For the second case of emissions leakage, I assess how incomplete regulation affects producers in the bilateral region by utilizing a similar definition for leakage:

$$
L=\sum_{i=1}\left(1-d_{i}\right) e_{i}\left(q_{G i, B}^{* *, R E G}-q_{G i, B}^{* *, 0}\right)
$$

I compare the emissions of producer $i$ when producer $j$ is regulated, to the emissions of producer $i$ when producer $j$ is unregulated. For the bilateral market design, summing across producers where the number of regulated producers is $\sum_{j \neq i} d_{j}=N_{1}$, and the number of unregulated producers is $\sum_{i=1}\left(1-d_{i}\right)=N_{0}$, leakage can be written as

$$
L=N_{0} \overline{e_{0}} \tau\left\{\frac{3 N_{1} \overline{e_{1}}}{2\left(2 N_{B}+1\right)}\right\}
$$

where if $N_{0}=1$ and $N_{1}=1$, the duopoly leakage condition for producers in the bilateral market is

$$
L=\tau\left(\frac{3 \overline{e_{0}}}{10}\right)
$$

The marginal effect of the increase in production cost from the permit price is less in the bilateral region than in the centralized region. In this way, the bilateral market acts as a backstop to leakage.

$$
\text { If } N_{0}=2 \text { and } N_{1}=2 \text {, the leakage condition becomes }
$$

$$
L=\tau\left(\frac{2 \overline{e_{0}} \overline{e_{1}}}{3}\right)
$$

which is less than leakage in the centralized market for an equivalent number of producers. In 
Appendix G, I present a case of emissions leakage in the bilateral market when the forward position is negative, finding leakage is less than in the bilateral market for an equivalent number of producers with positive forward positions.

PROPOSITION 7: Ceteris paribus, for the centralized region, incomplete regulation leads to higher emissions leakage than the bilateral region, in this sense, the bilateral region acts as a natural backstop to emissions leakage.

\subsection{Market equilibrium across market designs with trade}

In this section I will allow trade across market designs in the spot market at time $t=2$, allowing electricity to be supplied to the centralized region from the bilateral region, where the bilateral utilities will offer $Z_{B}$ to the centralized region, resembling the participation of producers in the bilateral region in the centralized spot market.

I assume that the surrounding bilateral market producers act as an oligopolistic fringe, supplying a portion of electricity to the centralized region, $Z_{B}$, which shifts the centralized region's residual demand. Given that in reality electricity markets are geographically distinct, customers cannot arbitrage electricity price differences across regions, and electricity transfers across regions are limited to an extent by availability of transmission, I assume the net-exporting producers in the bilateral market act in a price-discriminating manner-selling electricity within the bilateral region and to the centralized region but at two different prices.

\subsubsection{Centralized spot market with trade}

In the centralized spot market at time $t=2$, the $i$ th centralized producer's objective function is modified to reflect the residual demand shift, $Z_{B}$, from the electricity supplied by the bilateral region's oligopolistic fringe. The $i$ th producer's objective function is to maximize profits as before, but now also taking the residual demand shift, $Z_{B}$, from electricity supplied by the bilateral oligopolistic fringe as given.

$$
\begin{array}{r}
\max _{q_{G i, C}} \pi_{i, C}=\left(a_{C}-\tilde{Q}_{C}+\theta_{C}-Z_{B}-q_{G i, C}-\sum_{j \neq i}^{N_{C}} q_{G j, C}\right)\left(q_{G i, C}-f_{G i, C}\right)-c_{i}\left(q_{G i, C}-f_{G i, C}\right) \\
-c_{i} \gamma f_{G i, C}+\tau\left(A_{i}-d_{i} e_{i} q_{G i, C}\right)+p_{C}^{f} f_{G i, C}
\end{array}
$$


The Cournot-Nash equilibrium with the fringe supply of electricity is

$$
q_{G i, C}^{T r a d e *}=\frac{1}{N_{C}+1}\left\{a_{C}-\tilde{Q}_{C}+\theta_{C}-Z_{B}+\sum_{j \neq i}^{N_{C}}\left(c_{j}+\tau d_{j} e_{j}\right)-N_{C}\left(c_{i}+\tau d_{i} e_{i}\right)+f_{G i, C}\right\},
$$

where equilibrium output $\sum_{i=1}^{N_{C}} q_{G i, C}^{*}=Q_{G, C}^{*}$, is decreasing in the electricity supplied by the bilateral fringe producers.

\subsubsection{Centralized forward contract market with trade}

In the forward contract market, the optimal forward contract position is unchanged from equation (4), as I assume that trade occurs in the spot market only. ${ }^{24}$

The equilibrium forward contract price in the centralized market is affected by the supply of electricity from the bilateral oligopolistic fringe, as the forward contract market and spot market prices are linked because of financial arbitrage.

$$
p_{C}^{f *}-E\left(p_{C}^{s, T r a d e *}\right)=\frac{1}{N_{C}+1}\left\{a_{C}-\mu_{C}-Z_{B}+\sum_{i=1}^{N_{C}}\left(c_{i}+\tau d_{i} e_{i}\right)-Q_{R, C}^{*}\right\} .
$$

The bilateral oligopoly fringe's supply of electricity is also pro-competitive in the forward contract market, as it makes the forward contract market-clearing price more competitive.

Substituting the forward contract position into equation (14), the optimal quantity of electricity produced by the $i$ th centralized producer in the spot market with the fringe supply of electricity is

$$
q_{G i, C}^{T r a d e * *}=\frac{1}{N_{C}+1}\left\{a_{C}-\tilde{Q}_{C}+\theta_{C}-Z_{B}+\sum_{j \neq i}^{N_{C}}\left(c_{j}+\tau d_{j} e_{j}\right)-N_{C}\left(c_{i}+\tau d_{i} e_{i}\right)+q_{R i, C}^{*}\right\},
$$

where total production in the centralized market with trade is $\sum_{i=1}^{N_{C}} q_{G i, C}^{T r a d e * *}=Q_{G, C}^{T r a d e * *}$.

\subsubsection{Bilateral spot market with trade}

The price-discriminating bilateral producer now chooses how much electricity to supply to the bilateral market and the centralized market in its role as a member of the bilateral oligopoly fringe. As a member of the oligopoly fringe, the producer engages in Cournot competition with other exporting producers to supply to the centralized market. The producer also takes into account the effect that its

\footnotetext{
${ }^{24}$ In reality, trading across regions through bilateral contracts also occurs, but for the centralized market these bilateral contracts in the forward contract market are settled financially at the centralized market-clearing price FERC (2015), effectively increasing the number of producers participating in the centralized forward contract market.
} 
supply of electricity to the centralized region has on the spot market-clearing price in the centralized region. The bilateral producer's objective is to maximize its profits across the bilateral market segment (by choosing the optimal quantity of electricity to supply to the bilateral segment, $q_{G i, B}$ ) and the centralized market segment (by choosing how much electricity to export, $z_{i, B}$ ):

$$
\begin{aligned}
\max _{q_{G i, B}, z_{i, B}} \pi_{i, B}=\left(a_{B}-\tilde{Q}_{B}+\theta_{B}-\sum_{i=1}^{N_{B}} q_{G i, B}\right)\left(q_{G i, B}-f_{G i, B}\right)+p_{B}^{r} q_{R i, B} \\
+\left(a_{C}-\tilde{Q}_{C}+\theta_{C}-z_{i, B}-\sum_{j \neq i}^{N_{B}} z_{j, B}-\sum_{i=1}^{N_{C}} q_{G i, C}\right) z_{i, B}-c_{i}\left(q_{G i, B}+z_{i, B}-f_{G i, B}+q_{R i, B}\right) \\
-c_{i} \gamma f_{G i, B}+\tau\left(A_{i, B}-d_{i} e_{i}\left(q_{G i, B}+z_{i, B}\right)-d_{i} e_{i} q_{R i, B}\right)+p_{B}^{f} f_{R i, B}
\end{aligned}
$$

The Cournot-Nash equilibrium electricity production by the $i$ th bilateral producer in the bilateral spot market is then

$$
q_{G i, B}^{T r a d e *}=\frac{1}{N_{B}+1}\left\{a_{B}-\tilde{Q}_{B}+\theta_{B}+\sum_{j \neq i}^{N_{B}}\left(c_{j}+\tau d_{j} e_{j}\right)-N_{B}\left(c_{i}+\tau d_{i} e_{i}\right)+f_{G i, B}\right\}
$$

which is the same as in the bilateral spot market without trade because of the producer's ability to price discriminate across market segments.

The quantity of electricity the producer chooses to supply to the centralized market, $z_{i, B}$, is such that the Cournot-Nash equilibrium electricity production by the $i$ th bilateral producer as part of the oligopolistic fringe is

$$
z_{i, B}^{*}=\frac{1}{N_{B}+1}\left\{a_{C}-\tilde{Q}_{C}+\theta_{C}-Q_{G, C}^{T r a d e * *}+\sum_{j \neq i}^{N_{B}}\left(c_{j}+\tau d_{j} e_{j}\right)-N_{B}\left(c_{i}+\tau d_{i} e_{i}\right)\right\},
$$

where the total quantity of electricity supplied to the centralized market is $\sum_{i}^{N_{B}} z_{i, B}^{*}=Z_{B}^{*}$.

\subsubsection{Bilateral forward contract market with trade}

Because of the price-discriminating ability of the producers, and the assumption that the trade of electricity to the centralized market occurs only in the spot market at time $t=2$, the equilibrium forward contract position, forward contract market price, and spot market price for the bilateral region remain unchanged from those in Section 2.3.2. 


\subsubsection{Market equilibrium with trade across market designs}

In equilibrium, the price received by the bilateral fringe for electricity supplied to the centralized market is the centralized spot market-clearing price. For simplicity, I assume that no electricity is lost in trading across regions. Equilibrium across market designs requires finding the equilibrium amount of electricity supplied by the bilateral fringe to the centralized market at the market-clearing price. Substituting the centralized producers' total output, $Q_{G, C}^{T r a d e * *}$, into the $i$ th bilateral producer's optimal export choice, $z_{i, B}^{*}$, gives the equilibrium quantity of electricity exported by the $i$ th bilateral producer to the centralized region,

$$
\begin{aligned}
z_{i, B}^{* *}=\frac{1}{N_{B}+N_{C}+1}\left\{\left(a_{C}-\tilde{Q}_{C}+\theta_{C}\right)-\left(N_{B}\right.\right. & \left.\left.+N_{C}\right)\left(c_{i}+\tau d_{i} e_{i}\right)+\sum_{j \neq i}^{N_{B}}\left(c_{j}+\tau d_{j} e_{j}\right)\right\} \\
& +\frac{1}{N_{B}+N_{C}+1}\left\{N_{C}\left(c_{i}+\tau d_{i} e_{i}\right)-N_{C} Q_{R, C}^{*}\right\},
\end{aligned}
$$

and $\sum_{i=1}^{N_{B}}=Z_{B}^{* *}$ provides the equilibrium amount of electricity supplied to the centralized region in the spot market by the bilateral fringe.

Substituting $Z_{B}^{* *}$ back into equation (16) provides the equilibrium quantity of conventional electricity produced in the centralized spot market by producer $i$ when trading is allowed across markets:

$$
\begin{aligned}
q_{G i, C}^{T r a d e * * *}=\frac{1}{N_{B}+N_{C}+1}\left\{a_{C}-\tilde{Q}_{C}\right. & \left.+\theta_{C}-\left(N_{B}+N_{C}\right)\left(c_{i}+\tau d_{i} e_{i}\right)+\left(N_{C}-1\right)\left(c_{j}+\tau d_{j} e_{j}\right)\right\} \\
& +\frac{1}{N_{B}+N_{C}+1}\left\{N_{B}\left(c_{i}+\tau d_{i} e_{i}\right)+\left(N_{B}+1\right) Q_{R, C}^{*}\right\} .
\end{aligned}
$$

The centralized market becomes more competitive with the introduction of trade from the bilateral region, and the equilibrium quantity of conventional production is decreasing in the centralized regions' own costs but increasing in the bilateral regions' costs. The forward contract position serves to make the centralized producer even more competitive when trade is allowed.

The total quantity of electricity produced for export by the bilateral utility is $q_{G i, B}^{T r a d e * *}=$ $q_{G i, B}^{* *}+z_{i, B}^{* *}$.

Full derivations are shown in Appendix F. 


\subsection{Emissions Leakage with Trade}

\subsubsection{Case 3. Leakage to the bilateral region from regional regulation with trade}

In the third case of emissions leakage, I consider the case where the centralized market is the regulated region and the bilateral market is unregulated. I assume that producers $i$ and $j$ in the bilateral region are unregulated, and that producers $i$ and $j$ in the centralized region are regulated. In this case, leakage is defined as

$$
L^{B, T R A D E}=N_{0, B} \bar{e}_{0, B} \tau\left(\frac{N_{1, C} \bar{e}_{1, C}}{N_{B}+N_{C}+1}\right)
$$

If $N_{0, B}=2$ and $N_{1, C}=2$,

$$
L=\tau\left(\frac{4 \bar{e}_{0} \bar{e}_{1}}{5}\right)
$$

With trade, emissions leakage in the bilateral region increases:

$$
\underbrace{\tau\left(\frac{4 \bar{e}_{0} \bar{e}_{1}}{5}\right)}_{\text {ns Leakage Bilateral Trade }}>\underbrace{\tau\left(\frac{2 \bar{e}_{0} \bar{e}_{1}}{3}\right)}_{\text {Emissions Leakage Bilateral No Trade }} .
$$

Emissions leakage in the bilateral region increases with trade under incomplete regulation, as increased costs of spot market production in the regulated centralized market shift production to the bilateral fringe. The regulated region will send fossil-fuel production, and consequently emissions, out to the unregulated region, where production is less costly. Although emissions leakage increases, the unregulated bilateral producers also benefit from the price increase on rents from regulation. In Appendix G, I consider the case where the centralized market is the unregulated region and the bilateral market is regulated, finding that emissions leakage in the centralized region does not change with trade under incomplete regulation, as increased costs of spot market production in the regulated bilateral market make their costs equivalent to those in the centralized region.

PROPOSITION 8: With trade between regions, the regulated region will send fossil-fuel production, and consequently emissions, out to the unregulated region if costs are lower in the unregulated region. Ceteris paribus, for the regulated centralized region, trade with the unregulated bilateral region means that unregulated bilateral producers will benefit from the price increase on rents from regulation but that there will also be increased production and emissions. 


\section{NUMERICAL EXAMPLE AND WELFARE ANALYSIS OF KEY RESULTS}

I present a stylized example to highlight the key results of how centralized and bilateral market designs affect emissions leakage under incomplete regulation, and the resulting welfare implications. I consider the case of centralized duopolists and bilateral duopolists separately, focusing on the key results presented in Cases 1 and 2, respectively. All other emissions leakage cases presented are extensions of these two cases. For each market design—centralized or bilateral—I consider four different regulatory regimes: no regulation, complete regulation, incomplete regulation with only producer 1 regulated, and incomplete regulation with only producer 2 regulated. Regulation implies that producers pay a permit price $\tau$ per unit of emissions.

The parameters assumed for the numerical example are shown in Table 1, with $\tilde{Q}$ drawn from a normal distribution with $\mu=30$ and $\sigma_{\tilde{Q}}=4.6$, and $\theta$ drawn from a normal distribution with $\mathbb{E}(\theta)=0$ and $\sigma_{\theta}=5.1$, and $\operatorname{cov}(\tilde{Q}, \theta)=-1.33$.

Table 1: Parameters

\begin{tabular}{lccc}
\hline Centralized & \multicolumn{3}{c}{ Bilateral } \\
\hline$a_{C}$ & 100 & $a_{B}$ & 100 \\
$\tilde{Q}_{C}$ & 35 & $\tilde{Q}_{B}$ & 35 \\
$\theta_{C}$ & 9 & $\theta_{B}$ & 9 \\
$c_{1}, c_{2}$ & 1 & $c_{1}, c_{2}$ & 1 \\
$\gamma$ & 1 & $\gamma$ & 1 \\
$d_{1}, d_{2}$ & 0 or 1 & $d_{1}, d_{2}$ & 0 or 1 \\
$e_{1}, e_{2}$ & 1 & $e_{1}, e_{2}$ & 1 \\
$q_{R 1}, q_{R 2}$ & 25 & $q_{R 1}, q_{R 2}$ & 25 \\
& & $\phi_{1}, \phi_{2}$ & 0.5 \\
& & $\alpha_{1}, \alpha_{2}$ & 0.95 \\
$\gamma$ & 1 & $\gamma$ & 1 \\
$\tau$ & 10 & $\tau$ & 10 \\
$N_{C}$ & 2 & $N_{B}$ & 2 \\
\hline
\end{tabular}

Figure 2 plots the best response functions of producer 1 and producer 2 in the two-stage game in the centralized market. The positive domain of the horizontal and vertical axes measure the quantity of electricity produced by producer 1 and producer 2 , respectively. The black, downward sloping lines represent the best response functions of producer 1 and producer 2 in the case of no regulation. The intersection of the black lines (point A) defines the Cournot equilibrium quantities of electricity produced under no regulation, where $\left(q_{G 1, C}, q_{G 2, C}\right)=\left(32 \frac{2}{3}, 32 \frac{2}{3}\right)$. The red downward sloping lines represent the best response functions of producer 1 and producer 2 in the case of complete regulation. The intersection of the red dashed lines (point B) defines the Cournot equilibrium quantities of electricity produced under complete regulation, where $\left(q_{G 1, C}, q_{G 2, C}\right)=\left(29 \frac{1}{3}, 29 \frac{1}{3}\right)$. 
Under incomplete regulation, when only producer 1 is regulated, equilibrium production is defined by point $\mathrm{C},\left(q_{G 1, C}, q_{G 2, C}\right)=(26,36)$. When only producer 2 is regulated, equilibrium production is defined by point $\mathrm{D},\left(q_{G 1, C}, q_{G 2, C}\right)=(36,26)$.

Each firm's emissions are shown on the negative domain of Figure 2. For simplicity, I assume one unit of emissions per unit of output. Emissions and emissions leakage are measured by the rectangular areas $E$ though $L$. Under no regulation, emissions are equal to $E+F+G+J+K+L$ $=65 \frac{1}{3}$. Complete regulation, with emissions $E+F+K+L=58 \frac{2}{3}$, reduces emissions by $G+J=6 \frac{2}{3}$. Incomplete regulation, when only producer 1 is regulated (equilibrium point $\mathrm{C}$ ), results in emissions $E+I+J+K+L=62$, resulting in emissions, $I+J=6 \frac{2}{3}$, from producer 2 , that exceed emissions reductions, $F=3 \frac{1}{3}$, from producer 1 . Similarly, when only producer 2 is regulated (equilibrium point D), emissions leakage from producer 1 is equal to $G+H=6 \frac{2}{3}$, which exceeds emissions reductions from producer 2 of $K=3 \frac{1}{3}$, for total emissions leakage of $3 \frac{1}{3}$, which is equivalent to the duopoly leakage condition for the centralized market with $\tau=10$.

\section{Figure 2: Centralized Market Duopoly Example}

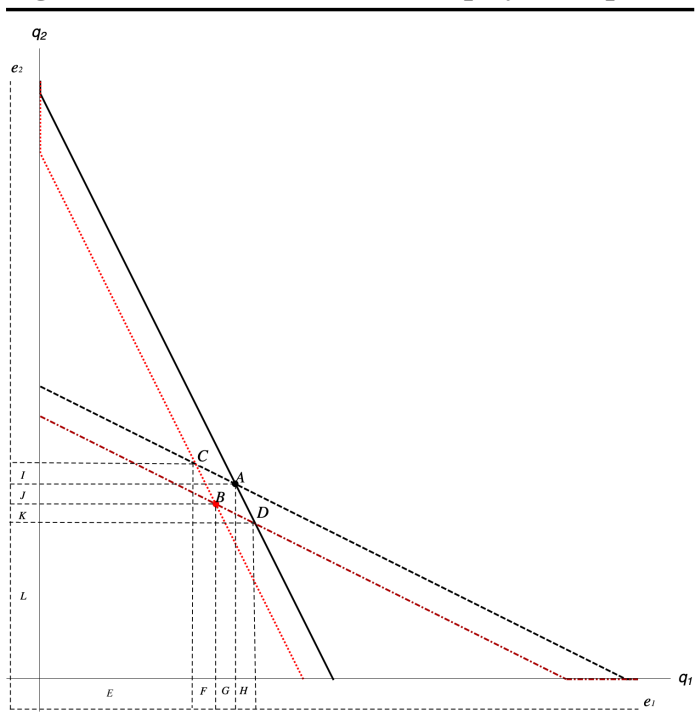

Notes: This figure plots the best response functions of producer 1 and producer 2 in the two-stage game in the centralized market under no regulation (solid black lines) and complete regulation (red dashed lines). The positive domain of the horizontal and vertical axes measure the quantity of electricity produced by producer 1 and producer 2 , respectively.
Figure 3: Bilateral Market Duopoly Example

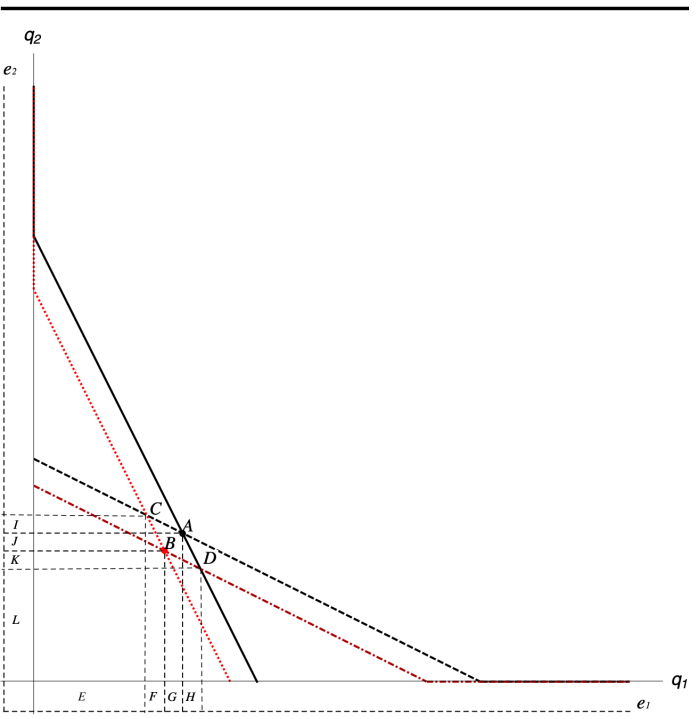

Notes: This figure plots the best response functions of producer 1 and producer 2 in the two-stage game in the bilateral market under no regulation (solid black lines) and complete regulation (red dashed lines). The positive domain of the horizontal and vertical axes measure the quantity of electricity produced by producer 1 and producer 2 , respectively.

Figure 3 plots the best response functions of producer 1 and producer 2 in the two-stage game in the bilateral market. The positive domain of the horizontal and vertical axes measure the quantity of electricity produced by producer 1 and producer 2, respectively. The intersection of the black lines (point A) defines the Cournot equilibrium quantities of electricity produced under no regulation, where 
$\left(q_{G 1, C}, q_{G 2, C}\right)=(25,25)$. The intersection of the red lines (point B) defines the Cournot equilibrium quantities of electricity produced under complete regulation, where $\left(q_{G 1, C}, q_{G 2, C}\right)=(22,22)$. Under incomplete regulation, when only producer 1 is regulated, equilibrium production is defined by point $\mathrm{C},\left(q_{G 1, C}, q_{G 2, C}\right)=(19,28)$. When only producer 2 is regulated, equilibrium production is defined by point $\mathrm{D},\left(q_{G 1, C}, q_{G 2, C}\right)=(28,19)$.

Each firm's emissions are shown on the negative domain of Figure 3. For simplicity, I assume one unit of emissions per unit of output. Emissions and emissions leakage are measured by the rectangular areas $E$ through $L$. Under no regulation, emissions are equal to $E+F+G+J+K+$ $L=50$. Complete regulation, with emissions $E+F+K+L=46$, reduces emissions by $G+J=6$. Incomplete regulation, when only producer 1 is regulated (equilibrium point $\mathrm{C}$ ), results in emissions $E+I+J+K+L=47$, resulting in emissions, $I+J=6$, from producer 2, that exceed emissions reductions, $F=3$, from producer 1 . Similarly, when only producer 2 is regulated (equilibrium point D), emissions leakage from producer 1 is equal to $G+H=6$, which exceeds emissions reductions from producer 2 of $K=3$, for total emissions leakage of 3, which is equivalent to the duopoly leakage condition for the bilateral market with $\tau=10$.

I conduct the welfare analysis by comparing a baseline case, $Q_{k}^{0}$, of no regulation to the cases of incomplete regulation, and complete regulation, in region $k$ (where $k=C$ or $k=B$ for the centralized or bilateral region, respectively). For incomplete regulation, I assume producer 1 is regulated and producer 2 is unregulated.

I adopt a welfare measure similar to Fowlie (2009), where welfare is defined as the gross benefits the consumer receives from consuming electricity, $\int_{0}^{Q_{C}(d 1, d 2)} D(s) d s$, less the costs of production, $\sum_{i=1}^{2} c_{i} q_{i}(d 1, d 2)$, and damages from emissions, $\tau \sum_{i=1}^{2} e_{i} q_{i}(d 1, d 2)$, where emissions damages have an emissions price, $\tau$. I assume the regulator weights consumer and producer surplus equally, ignoring any distributional effects.

The regulator maximizes social welfare with the objective function:

$$
W_{k}(d 1, d 2)=\int_{0}^{Q_{k}(d 1, d 2)} D(s) d s-\sum_{i=1}^{2} c_{i} q_{i}(d 1, d 2)-\tau \sum_{i=1}^{2} e_{i} q_{i}(d 1, d 2) .
$$

Incomplete regulation is net welfare improving if the change in welfare from regulating producer $1,\left(W_{C}(1,0)\right)$, compared to the case of no regulation $\left(W_{C}(0,0)\right)$, is positive.

$$
W_{C}(1,0)-W_{C}(0,0)=\int_{Q_{C}^{* *, 0}}^{Q_{C}^{* *, R e g}} p_{C}^{s}(s) d s+\frac{\tau}{3} e_{1}\left(2 c_{1}-c_{2}\right)+\frac{\tau^{2}}{3}\left(2 e_{1}^{2}-e_{1} e_{2}\right) .
$$


The first term is the change in consumer surplus from consuming total electricity $Q_{C}^{* *}$, the second term is the change in marginal costs from regulating producer 1 , as well as reallocating production from producer 1 to producer 2 , and the third term is the change in emissions damages from pricing producer 1's emissions. For symmetric firms, the first term is unambiguously negative as regulation reduces the total amount of electricity produced. The second term is unambiguously positive, as reduced output lowers production costs. The third term is also unambiguously positive as reduced output reduces emissions damages. Comparing the change in welfare from complete regulation $\left(W_{C}(1,1)-W_{C}(0,0)\right.$, solid black line) to incomplete regulation $\left(W_{C}(1,0)-W_{C}(0,0)\right.$, red dashed line) in Figure 4, at low emissions levels, regulation is welfare reducing, due to the welfare costs of reduced output, but becomes welfare enhancing at higher levels of emissions. Complete regulation dominates incomplete regulation for all levels of emissions.

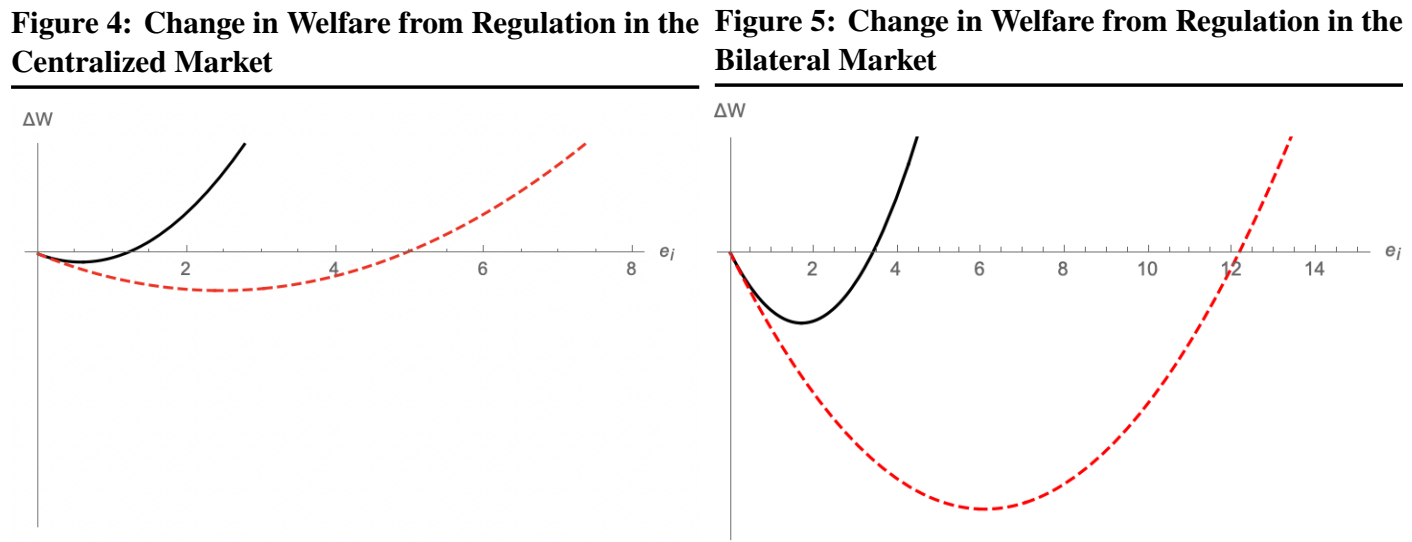

Notes: This figure depicts the change in welfare for complete (solid Notes: This figure depicts the change in welfare for complete (solid black line) and incomplete regulation (red dashed line), compared black line) and incomplete regulation (red dashed line), compared to the base case of no regulation for the centralized market. to the base case of no regulation for the bilateral market.

In the bilateral market, incomplete regulation is net welfare improving if the change in welfare from regulating producer $1, W_{B}(1,0)$, compared to the case of no regulation, $W_{B}(0,0)$, is positive.

$$
W_{B}(1,0)-W_{B}(0,0)=\int_{Q_{B}^{* *, 0}}^{Q_{B}^{* *, R e g}} p_{B}^{s}(s) d s+\frac{3 \tau}{10} e_{1}\left(2 c_{1}-c_{2}\right)+\frac{3 \tau^{2}}{10}\left(2 e_{1}^{2}-e_{1} e_{2}\right)
$$

Where, similar to the centralized market, the first term is the change in consumer surplus from consuming total electricity $Q_{B}^{* *}$, and is unambiguously negative from reduced electricity production, the second term is the change in marginal costs from regulating producer 1 and reallocating production from producer 1 to producer 2 , and is unambiguously positive, and the third term is the change in emissions damages from pricing producer 1's emissions, which is also unambiguously positive for 
symmetric firms. Comparing the change in welfare from complete regulation $\left(W_{B}(1,1)-W_{B}(0,0)\right)$, solid black line) to incomplete regulation $\left(W_{B}(1,0)-W_{B}(0,0)\right.$, red dashed line) in Figure 5 , at low emissions levels, regulation is welfare reducing, due to the welfare costs of reduced output, but becomes welfare enhancing at higher levels of emissions. Complete regulation dominates incomplete regulation for all levels of emissions.

Comparing welfare in the centralized market to welfare in the bilateral market, complete regulation is welfare enhancing at lower levels of emissions in the centralized market than the bilateral market. In the less-competitive bilateral market, the welfare costs of reducing output are initially more severe, and outweigh the benefits of reducing marginal costs of production and emissions damages until emissions reach a higher level than found in the centralized market. With incomplete regulation, this effect is exaggerated. Reallocating production from producer 1 to producer 2 reduces welfare in both markets, but more so in the bilateral market. However, in both markets, high enough permit prices, $\tau$, make the change in welfare for complete and incomplete regulation positive for all levels of emissions.

\section{CONCLUSION}

I develop a theoretical model to examine how different market designs affect strategic behavior and resulting emissions leakage under a regional climate policy. I utilize a two-stage model of oligopolistic electricity production to determine if strategic behavior in forward contract and spot markets across differing electricity market designs increases or decreases emissions leakage from regional climate policies. By examining emissions leakage from an incomplete carbon cap-and-trade regulation under differing market designs, where markets can be either centralized and arbitrage is allowed, or bilateral and arbitrage is not allowed, between time periods one and two.

My main finding is that emissions leakage depends on the relative market power in centralized vs. bilateral regions. I find that uncertainty from demand and renewable resource shocks leads to more or less market power, depending on the market design. Relative market power is driven by market design, where centralized markets are more competitive for a given number of players. When a carbon emissions price is asymmetrically applied to the bilateral region, emissions leakage is low. When a carbon emissions price is asymmetrically applied to a centralized region, emissions leakage is high. If a carbon emissions price is applied to a centralized region, and emissions leakage is to a bilateral region, leakage is again low but increases if the bilateral region trades with the centralized region. Emissions leakage increases in more competitive markets, because producers' production 
and relative market shares are more responsive to relative changes in marginal costs as in Fowlie (2009), but the less competitive bilateral market can act as a structural backstop to emissions leakage. Not accounting for differences in market design can affect emissions leakage and potentially render climate policy goals ineffective.

These results are important for continuing electricity market reforms that aim to integrate diverse electricity market designs, but also integrate regions with varying regional climate policies. For example, CAISO is currently considering extending EIM participants access to its larger day-ahead markets with the extended day-ahead market initiative. SPP recently launched its Western Energy Imbalance Services market, allowing more utilities from the traditionally bilateral Western electric region to join a centralized spot market. The European Union's Energy Union also continues to further integrate diverse member states' energy markets to support the clean energy transition.

Some caveats are that simplifying assumptions of normality of profits, symmetry of firms, absence of transmission constraints, and consideration of only the interior solution-assumptions that are made to gain tractability in the model—can affect results. The results are most appropriate for understanding short-term implications of regional climate policies under different market designs with small amounts of trade across regions. I leave performing more realistic numerical simulations of the model on electricity data to quantify larger-scale impacts of regional climate policies under different market designs to future work.

A defining feature of this model is that the availability of financial instruments to facilitate price arbitrage in some electricity markets enhances the competitiveness of those markets. These financial instruments are crucial because of the lack of meaningful amounts of storage currently available in electricity markets. Future advancements in storage technology and availability could change the competitive landscape of electricity markets, potentially addressing current differences in market design which stem from a lack of participation by financial speculators.

\section{ACKNOWLEDGEMENTS}

Thanks to Charles F. Mason, Ben Gilbert, Thorsten Janus, Robert Godby, Klaas van 't Veld, seminar participants at the WEAI 95th Conference, and three anonymous reviewers for valuable comments. 


\section{REFERENCES}

Allaz, B., 1992. Oligopoly, uncertainty and strategic forward transactions. International Journal of Industrial Organization 10, 297-308.

Allaz, B., Vila, J.L., 1993. Cournot competition, forward markets and efficiency. Journal of Economic theory 59, 1-16.

Anderson, E.J., 2013. On the existence of supply function equilibria. Mathematical Programming 140, 323-349.

Anderson, R.W., Danthine, J.P., 1980. Hedging and joint production: Theory and illustrations. The Journal of Finance 35, 487-498. doi:10.1111/j.1540-6261.1980.tb02180.x.

Andersson, B., Bergman, L., 1995. Market structure and the price of electricity: An ex ante analysis of the deregulated swedish electricity market. The Energy Journal , 97-109.

Artzner, P., Delbaen, F., Eber, J.M., Heath, D., 1999. Coherent measures of risk. Mathematical Finance 9, $203-228$.

Bessembinder, H., Lemmon, M.L., 2002. Equilibrium pricing and optimal hedging in electricity forward markets. the Journal of Finance 57, 1347-1382.

Borenstein, S., Bushnell, J., Knittel, C.R., 1999. Market power in electricity markets: Beyond concentration measures. The Energy Journal , 65-88.

Bushnell, J., Chen, Y., 2012. Allocation and leakage in regional cap-and-trade markets for CO 2. Resource and Energy Economics 34, 647-668.

Bushnell, J., Chen, Y., Zaragoza-Watkins, M., 2014. Downstream regulation of CO 2 emissions in California's electricity sector. Energy Policy 64, 313-323.

Bushnell, J., Mansur, E., Saravia, C., 2008. Vertical Arrangments, Market Structure, and Competition: An Analysis of Restructured US Electricity Markets. American Economic Review 98, 237-266. doi:10.1257/aer .98.1.237.

Bushnell, J., Wolak, F., 2006. Convergence Bidding and the Enforcement of Day-Ahead Commitments in Electricity Markets. California Independent System Operator.

Bushnell, J.B., Mansur, E.T., 2011. Vertical targeting and leakage in carbon policy, in: American Economic Review, pp. 263-267. doi:10.1257/aer.101.3.263.

Cardell, J.B., Hitt, C.C., Hogan, W.W., 1997. Market power and strategic interaction in electricity networks. Resource and Energy Economics 19, 109-137.

Chen, Y., Hobbs, B.F., 2005. An oligopolistic power market model with tradable NOX permits. IEEE Transactions on Power Systems 20, 119-129.

Chen, Y., Liu, A.L., Hobbs, B.F., 2011. Economic and emissions implications of load-based, source-based, and first-seller emissions trading programs under california ab32. Operations Research 59, 696-712.

Di Maria, C., Lange, I., Lazarova, E., 2016. A look upstream: Market restructuring, risk, procurement contracts and efficiency . Downward, A., 2010. Carbon charges in electricity markets with strategic behavior and transmission. The Energy Journal 31.

FERC, 2015. Energy primer: A handbook of energy market basics. the division of energy market oversight. http: //www.ferc.gov/market-oversight/guide/energy-primer.pdf. 
Fowlie, M.L., 2009. Incomplete environmental regulation, imperfect competition, and emissions leakage. American Economic Journal: Economic Policy 1, 72-112.

Green, R., 1999. The electricity contract market in england and wales. The Journal of Industrial Economics 47, 107-124.

Green, R.J., Newbery, D.M., 1992. Competition in the british electricity spot market. Journal of Political Economy 100, 929-953.

Hausman, E., Hornby, R., Smith, A., 2008. Bilateral contracting in deregulated electricity markets. Technical Report.

Hirshleifer, D., Subrahmanyam, A., 1993. Futures versus share contracting as means of diversifying output risk. The Economic Journal 103, 620-638.

Holmberg, P., 2008. Unique supply function equilibrium with capacity constraints. Energy Economics 30, 148-172.

Hortaçsu, A., Puller, S.L., 2008. The RAND Corporation Understanding Strategic Bidding in Multi-Unit Auctions : A Case Study of the Texas Electricity Spot Market. The RAND Journal of Economics 39, 86-114.

Jha, A., Wolak, F.A., 2013. Testing for market efficiency with transactions costs: An application to convergence bidding in wholesale electricity markets, in: Industrial Organization Seminar at Yale University, April, Citeseer.

Klemperer, P.D., Meyer, M.A., 1989. Supply function equilibria in oligopoly under uncertainty. Econometrica: Journal of the Econometric Society, 1243-1277.

Kreps, D.M., Scheinkman, J.A., 1983. Quantity precommitment and bertrand competition yield cournot outcomes. The Bell Journal of Economics, 326-337.

Levy, H., Markowitz, H.M., 1979. Approximating expected utility by a function of mean and variance. The American Economic Review 69, 308-317.

Li, G., Shi, J., Qu, X., 2011. Modeling methods for genco bidding strategy optimization in the liberalized electricity spot market-a state-of-the-art review. Energy 36, 4686-4700.

Mansur, E.T., White, M., 2012. Market organization and efficiency in electricity markets. Work. Pap., Dartmouth Univ., Hanover, NH. http://www. dartmouth. edu/ mansur/papers/mansur_white_pjmaep. htm .

Powell, A., 1993. Trading Forward in an Imperfect Market: The Case of Electricity in Britain. The Economic Journal (London) $103,444-453$.

Puller, S.L., 2007. Pricing and firm conduct in california's deregulated electricity market. The Review of Economics and Statistics 89, 75-87.

Rockafellar, R.T., Uryasev, S., 2000. Optimization of conditional value-at-risk. Journal of Risk 2, 21-42.

Rockafellar, R.T., Uryasev, S., 2002. Conditional value-at-risk for general loss distributions. Journal of Banking \& Finance 26, $1443-1471$

Rose, K., Tarufelli, B., Upton, G., 2020. Electricity market restructuring and retail rates. USAEE Working Paper .

Sweeting, A., 2007. Market power in the england and wales wholesale electricity market 1995-2000. The Economic Journal $117,654-685$.

Willems, B., Rumiantseva, I., Weigt, H., 2009. Cournot versus supply functions: What does the data tell us? Energy Economics $31,38-47$. 